\title{
BMJ Open Prevalence of disposable pod use and consumer preference for e-cigarette product characteristics among vape shop customers in Southern California: a cross-sectional study
}

\author{
Artur Galimov (10 , ${ }^{1}$ Adam Leventhal, ${ }^{1,2}$ Leah Meza, ${ }^{1}$ Jennifer B. Unger, ${ }^{1}$ Jimi Huh, ${ }^{1}$ \\ Lourdes Baezconde-Garbanati, ${ }^{1}$ Steven Y Sussman ${ }^{1,3,4}$
}

To cite: Galimov A, Leventhal A, Meza L, et al. Prevalence of disposable pod use and consumer preference for ecigarette product characteristics among vape shop customers in Southern California: a crosssectional study. BMJ Open 2021;11:e049604. doi:10.1136/ bmjopen-2021-049604

- Prepublication history for this paper is available online To view these files, please visit the journal online (http://dx.doi. org/10.1136/bmjopen-2021049604).

Received 28 January 2021 Accepted 16 September 2021

Check for updates

(C) Author(s) (or their employer(s)) 2021. Re-use permitted under CC BY-NC. No commercial re-use. See rights and permissions. Published by BMJ.

${ }^{1}$ Department of Population and Public Health Sciences, University of Southern California Keck School of Medicine, Los Angeles, California, USA ${ }^{2}$ Institute for Addiction Science, University of Southern California, Los Angeles, CA, USA

${ }^{3}$ Department of Psychology, University of Southern California, Los Angeles, CA, USA

${ }^{4}$ School of Social Work, University of Southern California, Los Angeles, CA, USA

Correspondence to

Dr Artur Galimov;

galimov@usc.edu

\section{ABSTRACT}

Objectives In February 2020, the US Food and Drug Administration issued a guidance restricting the sales and distribution of cartridge-based e-cigarettes with flavours other than tobacco and menthol. Disposable devices were exempt from this guidance. This study examined the prevalence of disposable pod use and flavour preference compared with refillable pod and other e-cigarette users among vape shop customers.

Design Cross-sectional study.

Setting In July 2019-March 2020, trained data collectors visited 44 vape shops in California with permission to recruit customers from shop owners.

Participants Intercept interviews with 276 customers were conducted.

Outcomes and procedures Customers were grouped based on self-reported device type used most often (disposable pod, refillable pod and other e-cigarettes). Groups were compared on self-reported demographics, flavours preferred, daily e-cigarette use, preferred nicotine concentration levels and cigarette use.

Results Of the 276 customers surveyed, $11.2 \%$ used disposable pods in the past 30 days. Among disposable pod users, fruit/candy (80.7\%), mint (77.4\%) and menthol (67.7\%) were common preferred flavours, while tobacco flavours were less commonly preferred (19.4\%). When compared with refillable pod and other non-pod e-cigarette device users, disposable pod users were younger, used higher nicotine concentration levels, were more likely to prefer mint and menthol flavours and use e-cigarettes as their first product, while less likely to ever use cigarettes and use ecigarettes daily.

Discussion Despite using higher nicotine levels and preferred menthol/mint flavours more often than users of other devices, disposable pod users reported lower prevalence of lifetime smoking and daily vaping and were younger. Given the current findings, regulations addressing non-tobacco flavours and nicotine concentration in disposable pod devices merit consideration in efforts to reduce vaping in younger adult never smokers.

\section{Strengths and limitations of this study}

- This is one of the first studies to examine the consumer preferences for e-cigarette product characteristics and flavour preference of disposable pod users.

- The presented results are suitable to guide future regulatory changes that would limit non-tobacco flavours, as well as the maximum nicotine concentration in disposable pod devices.

- This study is limited in sample size, and our findings might not be generalisable to vapers outside the Southern California area.

\section{INTRODUCTION}

Sales of electronic cigarettes (e-cigarettes) have rapidly increased in recent years, and their prevalence has surpassed combustible tobacco use among youth and young adults. ${ }^{1}$ One factor that may contribute to the surge of e-cigarette use is a rapid evolution and diversity of vaping products. Within the last 10 years, vaping devices have progressed from thin, cig-a-like disposable devices (first generation), to tubular, refillable vape pen devices (second generation), to box mod (third generation) and to pod mod (JUUL type) devices. ${ }^{2}$ In particular, pod mods are small, low-powered, high-nicotine devices that are available in numerous flavours (such as mint, fruit), which have become prevalent among minors and emerging adults. ${ }^{34}$ To counteract the youth e-cigarette use epidemic, in February 2020, the US Food and Drug Administration issued a final guidance indicating that the manufacture, distribution and sale of prefilled cartridge-based (ie, JUUL, Phix) e-cigarettes without marketing authorisation in flavours other than tobacco and menthol would be prioritised for enforcement of 
unlawful marketing of unauthorised products. ${ }^{5}$ Nonetheless, public health professionals have raised concerns because language in the guidance failed to include disposable pod devices. ${ }^{6}$

Disposable pod-style devices (ie, Puff Bar, Ignite, Lush) are compact, sleek, ready-to-use, prefilled vaping devices that contain $20-70 \mathrm{mg} / \mathrm{mL}$ of nicotine salt and are marketed to deliver $200-300$ puffs per device. ${ }^{7}$ They are priced as low as US\$4.60 and are available in mango, mint, strawberry and many other fruit/candy novel flavours with attractive packaging that may be appealing to minors and young adults. ${ }^{7}$ While there is some evidence suggesting that more e-cigarette users may be replacing the flavoured cartridge-based vaping devices with disposable pod devices, ${ }^{8}$ and their prevalence is increasing among middle and high school youth, ${ }^{9}$ little is known regarding the flavour preferences of disposable pod users.

To inform future flavour and other regulations of podstyle devices, we assessed the prevalence of disposable pod use and flavour preference among vape shop customers using intercept interviews, in real time, as customers exited the vape shop. Additionally, we examined the differences in consumer preference for e-cigarette product characteristics between disposable pod users, refillable pod product users and other e-cigarette users. We hypothesised that disposable pod users would prefer higher nicotine concentration levels and would be more likely to prefer mint and menthol flavours compared with refillable pod and other e-cigarette device users.

\section{METHODS}

\section{Participants and procedures}

A list of eligible vape shops located in Southern California was generated from Google Maps and Yelp in locations with relatively high proportion of residents representing four ethnic groups (based on US Census data) ${ }^{10}$ From July 2019 to March 2020 (prior to COVID-19 shutdowns), two or three trained data collectors visited a subsample of 44 vape shops between 10:00 and 17:00 hours during workdays with permission to recruit customers from shop owners. All vape shop customers present at the time of data collection were approached by data collectors as they exited the vape shop $(n=425)$. Eligible participants were those who reported having vaped in the past 30 days and agreed to participate in a $15 \mathrm{~min}$ interview. Participants provided verbal consent prior to taking the survey and were informed that their responses would be kept anonymous. On survey completion, participants received a US $\$ 35$ gift card. A total of 401 eligible customers were invited to participate in this study, 276 of them (69\%) agreed and were recruited for participation in the customer interviews. The participants that took the survey did not differ from those who refused to participate in the study by any sociodemographic factor except for age. That is, subjects that participated in the study were significantly younger than those who refused to take the survey $(\mathrm{p}=0.001)$.

\section{Measures}

Self-reported measures of gender, age and ethnicity were obtained from each participant. Past 30-day e-cigarette use was assessed with the item: 'In the past 30 day, on how many days did you use e-cigarettes?' (1-30 days). The most frequently used type of e-cigarette device (used in the past 30 days) was assessed by asking participants: 'What type of e-cigarette device do you use most often?' (open-ended and further coded into the following categories: pen, box mod, disposable pod style, refillable pod mod or other). Only $3(1.0 \%)$ participants selected 'other' and reported (equally) using both refillable pods and box mods; for analyses purposes they were classified as box mod users. Responses were recoded into a primary exposure variable with three mutually exclusive categories (disposable pod vs refillable pod vs other devices (pen and box mod)). Additionally, participants were asked to indicate the first nicotine-containing product they used in their life (ie, e-cigarette, cigarette or other tobacco product).

Participants' e-liquid flavour preference was assessed with the question, 'Which types of e-juices do you like the most? (Check all that apply)'. The response categories included: 'fruit/candy', 'dessert', 'minty flavours', 'menthol' and 'tobacco flavour'. Additionally, we evaluated the preferred e-liquid nicotine level by asking participants: 'How many $\mathrm{mg}$ per $\mathrm{mL}$ of nicotine does your favourite brand/flavour have?' (Open-ended, for example, $0,3,6,9,12,18,24,25,50 \mathrm{mg} / \mathrm{mL})$.

\section{Data analysis}

The prevalence of e-cigarette use, demographic characteristics and flavour preference of disposable pod users were reported for the full sample of participants. Further, the three groups of users (disposable pod users, refillable pod users and users of other e-cigarette products) were compared regarding demographics, flavour preference, daily e-cigarette use, preferred nicotine concentration levels and cigarette use. Pearson's $\chi^{2}$ tests were calculated for categorical study variables, while analysis of variance tests were calculated for continuous variables. Statistically significant variables were then included as dependent variables in multilevel regression analyses with type of device used (ie, disposable pods, refillable pod users and other e-cigarette devices) as a predictor, while controlling for the nesting of vape shop customers (level 1) within 44 vape shops (level 2). All models were adjusted for sociodemographic factors. Maximum likelihood estimation was used to account for non-normal distributions and missing data. ORs and beta coefficients ( $\beta$ s) with $95 \%$ CIs were reported with statistical significance set at $\mathrm{p}<0.05$ (two tailed). Benjamini-Hochberg multiple-testing corrections were applied to control the false-discovery rate at .05 . All statistical analyses were conducted using Stata software (V.15.1; StataCorp). 


\section{Patient and public involvement}

Patients or the public were not involved in the design, conduct, reporting, or dissemination plans of this study.

\section{RESULTS}

Of the 276 customers surveyed, $76.5 \%$ were males, with a mean age of 31.8 years $(\mathrm{SD}=10.5$, range $18-66) ; 35.9 \%$ were non-Hispanic white, $18.1 \%$ were Asian, $19.2 \%$ were Hispanic/Latino, 9.4\% were African American/black and $17.4 \%$ were of other ethnicities (eg, Middle Eastern or multiracial). Most participants $(77.9 \%)$ reported using e-cigarettes every day in the past 30 days. Responses regarding the type of e-cigarette device used in past 30 days in the total sample illustrated that $31(11.2 \%)$ used disposable pods, $102(40.0 \%)$ used refillable pods and
$143(51.8 \%)$ used other e-cigarette devices, with the latter category including $129(46.7 \%)$ box mod users and 14 $(5.1 \%)$ vape pen users.

Bivariate comparisons between study variables and the type of e-cigarette device used by vape shops customers in past 30-days are reported in table 1. Disposable pod users tended to be younger than other (non-pod) device type users (mean age: 26.1 ( $\mathrm{SD}=7.9)$ vs 34.5 (10.9), $\mathrm{p}<0.001)$. Disposable pod users also preferred to use higher nicotine concentration levels (mean nicotine level: 41.6 (17.7) mg/ $\mathrm{mL}$ ) than refillable pod users $(26.4(18.0) \mathrm{mg} / \mathrm{mL})$ and other device type users $(5.2(6.9) \mathrm{mg} / \mathrm{ml}$, both $\mathrm{p}<0.001)$. Lifetime cigarette use was more prevalent among refillable pod users $(81.4 \%)$ compared with disposable pod users $(61.3 \%, \mathrm{p}=0.02)$. Refillable pod users $(78.3 \%)$ and

Table 1 Participant characteristics for the total sample and by e-cigarette device type*

\begin{tabular}{|c|c|c|c|c|c|c|}
\hline & \multirow[b]{2}{*}{ Total $n=276$} & \multicolumn{5}{|c|}{ E-cigarette device type } \\
\hline & & $\begin{array}{l}\text { Disposable pod } \\
(\mathrm{n}=31)\end{array}$ & $\begin{array}{l}\text { Refillable pod } \\
(n=102)\end{array}$ & $P$ value & Other $¥(n=143)$ & $P$ value§ \\
\hline \multicolumn{7}{|l|}{ Demographics } \\
\hline Age, mean (SD) & $31.8(10.5)$ & $26.1(7.9)$ & $29.7(9.5)$ & 0.08 & $34.5(10.9)$ & $<0.0019$ \\
\hline Male & $211(76.5 \%)$ & $26(83.9 \%)$ & $82(80.4 \%)$ & 0.67 & $103(72.0 \%)$ & 0.18 \\
\hline \multicolumn{7}{|l|}{ Race/ethnicity } \\
\hline Asian & $50(18.1 \%)$ & $6(19.4 \%)$ & $28(27.5 \%)$ & \multirow[t]{5}{*}{0.43} & $16(11.1 \%)$ & \multirow[t]{5}{*}{0.34} \\
\hline $\begin{array}{l}\text { African American/ } \\
\text { black }\end{array}$ & $26(9.4 \%)$ & $2(6.5 \%)$ & $7(6.9 \%)$ & & 17 (11.9\%) & \\
\hline Hispanic/Latino & $53(19.2 \%)$ & $5(16.1 \%)$ & $19(18.6 \%)$ & & $29(20.3 \%)$ & \\
\hline White & 99 (35.9\%) & $9(29.0 \%)$ & $34(33.3 \%)$ & & $56(39.2 \%)$ & \\
\hline Other & $48(17.4 \%)$ & $9(29.0 \%)$ & $14(13.7 \%)$ & & $25(17.5 \%)$ & \\
\hline Daily-e-cigarette use & $215(77.9 \%)$ & $14(45.2 \%)$ & $80(78.3 \%)$ & $0.001 \rrbracket$ & $121(84.6 \%)$ & $<0.0019$ \\
\hline Lifetime cigarette use & $209(75.7 \%)$ & $19(61.3 \%)$ & $83(81.4 \%)$ & $0.02 \uparrow$ & $107(74.8 \%)$ & 0.13 \\
\hline $\begin{array}{l}\text { Past 30-day cigarette } \\
\text { use }\end{array}$ & $61(22.1 \%)$ & $7(22.6 \%)$ & $28(27.5 \%)$ & 0.59 & $26(18.2 \%)$ & 0.57 \\
\hline $\begin{array}{l}\text { Preferred nicotine level } \\
(\mathrm{mg} / \mathrm{mL}) \text {, mean (SD) }\end{array}$ & $17.0(18.7)$ & $41.6(17.7)$ & $26.4(18.0)$ & $<0.001 \rrbracket$ & $5.2(6.9)$ & $<0.0019$ \\
\hline \multicolumn{7}{|c|}{ First nicotine containing product } \\
\hline E-cigarette & $32(11.6 \%)$ & $11(35.5 \%)$ & $9(8.8 \%)$ & \multirow[t]{2}{*}{0.0019} & $12(8.4 \%)$ & \multirow[t]{2}{*}{$<0.001 \rrbracket$} \\
\hline $\begin{array}{l}\text { Cigarette or other } \\
\text { tobacco product }\end{array}$ & $244(88.4 \%)$ & 20 (64.5\%) & $93(91.2 \%)$ & & $131(91.6 \%)$ & \\
\hline \multicolumn{7}{|l|}{ Flavour preference } \\
\hline Fruit/candy & $201(72.8 \%)$ & $25(80.7 \%)$ & 75 (73.5\%) & 0.42 & $101(70.6 \%)$ & 0.26 \\
\hline Dessert & $91(33.0 \%)$ & $8(25.8 \%)$ & $26(25.5 \%)$ & 0.97 & 57 (39.9\%) & 0.15 \\
\hline Mint & 107 (38.8\%) & $24(77.4 \%)$ & 39 (38.2\%) & $<0.001 \rrbracket$ & 44 (30.8\%) & $<0.001 \rrbracket$ \\
\hline Menthol & $101(36.6 \%)$ & $21(67.7 \%)$ & $38(37.2 \%)$ & $0.004 \rrbracket$ & $42(29.4 \%)$ & $<0.0019$ \\
\hline Tobacco & $23(8.3 \%)$ & $6(19.4 \%)$ & $6(5.9 \%)$ & 0.03 & $11(7.7 \%)$ & 0.06 \\
\hline \multicolumn{7}{|c|}{$\begin{array}{l}\text { *Data are expressed as No (\%) unless otherwise indicated. } \\
\text { †For the difference between past } 30 \text {-day disposable pod users and past 30-day refillable pod users. } \\
\text { fOther devices include box mods and vape pens. } \\
\text { §For the difference between past } 30 \text {-day disposable pod users and other device type users. } \\
\text { IStatistically significant after Benjamini-Hochberg corrections for multiple testing to control false-discovery rate at } 0.05 \text { (based on two-tailed } \\
\text { corrected p value). }\end{array}$} \\
\hline
\end{tabular}


Table 2 Multilevel regression models examining the associations between type of e-cigarette device used and study variables

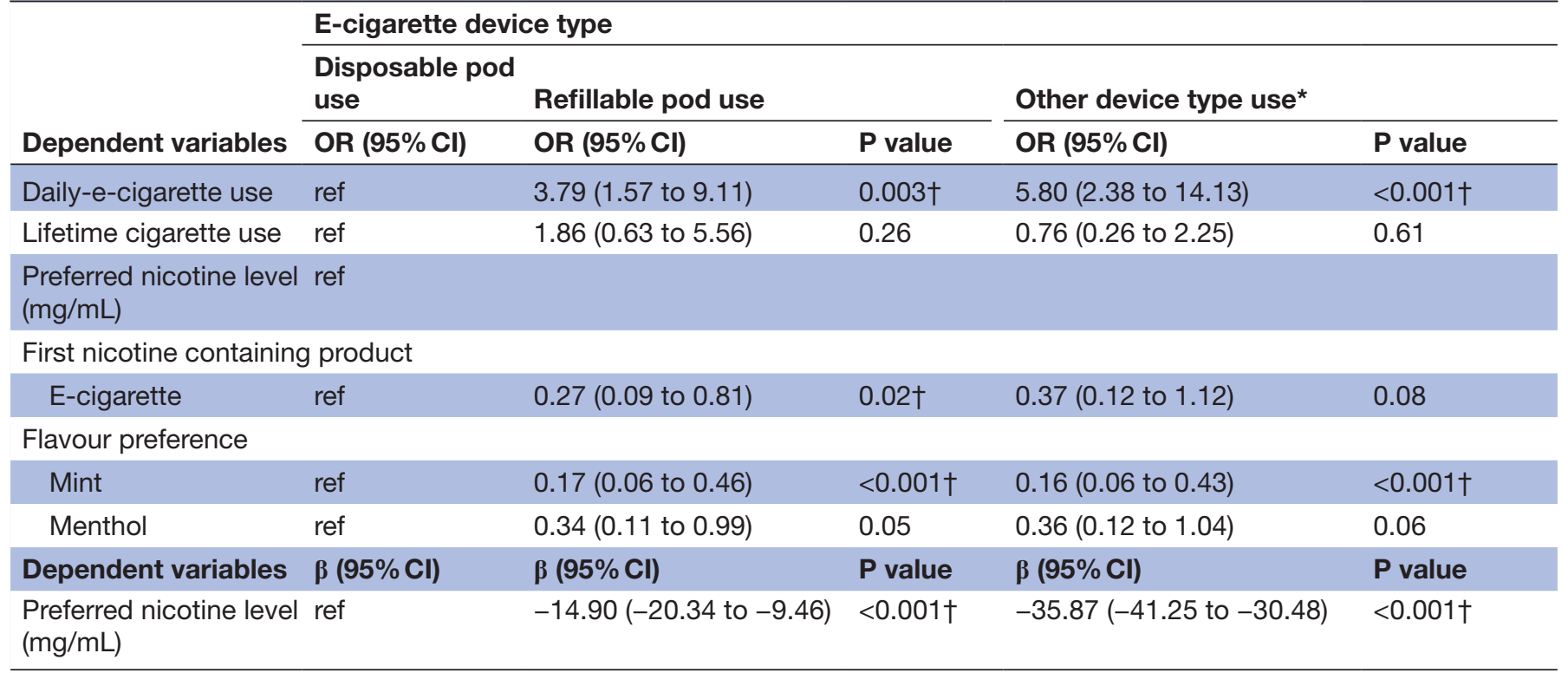

All models were adjusted for age, gender and ethnicity.

*Other devices include box mods and vape pens.

†Statistically significant after Benjamini-Hochberg corrections for multiple testing to control false-discovery rate at 0.05 (based on two-tailed corrected $p$ value).

other device type users $(84.6 \%)$ reported higher prevalence of daily e-cigarette use compared with disposable pod users $(45.2 \%$, both $\mathrm{p}<0.001)$. Additionally, disposable pod users reported higher prevalence of using e-cigarettes as their first nicotine containing product $(35.5 \%)$ than refillable pod $(8.8 \%)$ and other device type users $(8.4 \%$, both $\mathrm{p} \leq 0.001)$.

Fruit/candy $(80.7 \%)$, mint $(77.4 \%)$ and menthol $(67.7 \%)$ were the most preferred flavours among disposable pod users, while tobacco flavour $(19.4 \%)$ was the least preferred. In fact, a flavour preference of mint and menthol was more prevalent among disposable pod users compared with refillable pod users and other e-cigarette users (see table 1). Tobacco flavour preference was more prevalent among disposable pod users (19.3\%), compared with the other groups (see table 1). Post hoc analyses demonstrated that all disposable users who preferred tobacco flavours reported using combustible tobacco in their lifetime, and their mean age was 30.2 $(\mathrm{SD}=8.4)$ years.

The multilevel regression models (table 2) demonstrated that after adjusting for sociodemographic factors, refillable pod users (OR 3.79 (95\% CI 1.57 to 9.11 )) and other e-cigarette device type users (OR 5.80 (95\% CI 2.38 to 14.13)) were more likely to report daily e-cigarette use compared with disposable pod users. Further, e-liquid nicotine concentration preference was significantly lower among refillable pod users $(\beta=-14.90 \quad(95 \%$ CI $(-20.34$ to -9.46$))$ and other e-cigarette users $(\beta=-35.87(95 \%$ CI -41.25 to -30.48$)$ ) than among disposable pod users. Additionally, refillable pod users were less likely to report e-cigarette as their first nicotine containing product (OR
$0.27(95 \%$ CI 0.09 to 0.81$)$ ) than disposable pod users. Finally, it was shown that refillable pod users (OR 0.17 (95\% CI 0.06 to 0.46$)$ ) and other e-cigarette users (OR 0.16 (95\% CI 0.06 to 0.43$)$ ) were less likely to prefer mint flavours compared with disposable pod users.

\section{DISCUSSION}

In this sample of e-cigarette users who visited the vape shops in Southern California and self-reported using disposable pod devices, fruit/candy, mint and menthol were the most common preferred flavours. In fact, mint and menthol flavours were more prevalent among disposable pod users compared with the other e-cigarette users. Our results support findings from past studies that fruit-related, mint and menthol flavours are highly prevalent among e-cigarette users, while tobacco-related flavours are less prevalent, ${ }^{3}$ and extend results to vape shop customers that use disposable pod devices. Tobacco flavour was the least preferred e-liquid flavour among disposable pod users but was also more prevalent among these users compared with refillable pod users and other e-cigarette users. However, the comparison of tobacco flavour was not significant after controlling for multiple test correction and is qualified by the caveat of small cell size $(n=6)$. As a post hoc sensitivity analysis, we found that all six of these disposable pod users that reported liking tobacco flavours were former combustible tobacco users. This finding raises the possibility that some vape shop customers might use disposable pod devices with tobacco flavours as a means to quit smoking combustible tobacco, although the cross-sectional design and small 
size precludes definitive conclusion. Future research investigating whether smokers switch to disposable pod devices that might be less harmful alternative to smoking combustible cigarettes is warranted.

Additionally, our results indicate that disposable pod users reported using products with higher nicotine levels compared with the other e-cigarette users. This may be because such devices (eg, Puff Bar) are usually prefilled with $20-70 \mathrm{mg} / \mathrm{mL}$ salt-based nicotine e-liquid, ${ }^{7}$ while other e-cigarette devices can be used with either freebased $(0-12 \mathrm{mg} / \mathrm{mL})$ or salt-based nicotine $(>20 \mathrm{mg} / \mathrm{mL})$ e-liquid. ${ }^{2}$ Further, our data indicated that disposable pod users were younger, were less likely to use cigarettes in their lifetime and more likely to report e-cigarette as their first nicotine containing product than other e-cigarette users. This might suggest that Puff Bar-like devices are highly appealing to emerging adults, and other research indicates that disposable devices may also appeal to minors. ${ }^{4}$ For instance, one study demonstrated that the relative search volume for Puff Bar on Google Search has surpassed that of JUUL since February 2020, which may suggest that e-cigarette users are switching from cartridge-based e-cigarettes to disposable vaping products. ${ }^{8}$ Further, another study demonstrated that the prevalence of disposable pod use has increased from 3.0\% in 2019 to $15.2 \%$ in 2020 among middle school students and increased from $2.4 \%$ in 2019 to $26.5 \%$ in 2020 among high school students. ${ }^{9}$

This study has several limitations. Our findings might not be generalisable to vapers who obtain their e-cigarette products online, or through other types of brickand-mortar retail outlets, and do not visit vape shops, including youth $(<18$ years of age $)$ and those outside the Southern California. Subjects who participated in the study were significantly younger than those who refused to take the survey, thus our study findings may have limited generalisability to older vapers. Given the nature of the data, recall and social desirability biases may also have affected the results. The data collection halted because of COVID-19 human subject restrictions placed on research procedures; thus, it is unclear whether the same results will be observed in the post-COVID-19 period. The actual number of participants who used disposable pods was relatively small $(\mathrm{n}=31(11.2 \%))$, while the data were collected during a time of changing federal regulation of e-cigarette products ${ }^{5}$ (which led to the surge in disposable use prevalence); thus it is also not clear whether the same results will be observed 1 year after the data were collected. Despite the limitations, our study adds to the existing literature, providing a valuable source of information about the flavour preferences of disposable pod users.

In conclusion, these findings indicate that disposable pod users reported using products with higher nicotine levels and preferred mint and menthol flavours more often than users of other devices; nonetheless, disposable pod users reported lower prevalence of lifetime smoking and daily vaping, while were also younger. Given the current findings and previous studies showing sizeable proportions of youth use disposable pod e-cigarettes, future regulatory efforts addressing non-tobacco flavours and nicotine concentration in disposable pod devices merit consideration in efforts to reduce vaping in young populations and never smokers. Future research evaluating whether disposable pod use causes a greater risk for e-cigarette use experimentation and development of nicotine dependence is warranted.

Contributors All authors took an active role in the manuscript. SYS and LB-G designed the research. AG and LM conducted research under SYS supervision. LM coordinated the project. AG, AL and JH chose the main directions for data analysis and participated in the interpretation of results. AG performed the statistical analyses and drafted the manuscript. AL, LM, JU, JH, LB-G and SYS provided critical revision to the manuscript. AG, AL, LM, JU, JH, LB-G and SYS revised the manuscript before submission. All authors approved the final manuscript submitted.

Funding Research reported in this publication was supported by a California Tobacco-Related Disease Research Program Award (TRDRP Grant \#26IR-0016, Steve Sussman, PI) and a National Cancer Institute and FDA Center for Tobacco Products (CTP) Award (NCI/FDA Grant \#U54CA180905, Mary Ann Pentz and Adam Leventhal, PIs).

Disclaimer RDRP, $\mathrm{NCl}$, or the FDA had no role in the design and conduct of the study; collection, management, analysis, and interpretation of the data; preparation, review, or approval of the manuscript; and decision to submit the manuscript for publication.

\section{Competing interests None declared.}

Patient and public involvement Patients and/or the public were not involved in the design, or conduct, or reporting, or dissemination plans of this research.

Patient consent for publication Not required.

Ethics approval The study was approved by the USC Institutional Review Board (\#HS-18-00732).

Provenance and peer review Not commissioned; externally peer reviewed.

Data availability statement Data are available on reasonable request. Data are available on reasonable request. The data that support the findings of this study are available on request from the corresponding author.

Open access This is an open access article distributed in accordance with the Creative Commons Attribution Non Commercial (CC BY-NC 4.0) license, which permits others to distribute, remix, adapt, build upon this work non-commercially, and license their derivative works on different terms, provided the original work is properly cited, appropriate credit is given, any changes made indicated, and the use is non-commercial. See: http://creativecommons.org/licenses/by-nc/4.0/.

ORCID iD

Artur Galimov http://orcid.org/0000-0002-9718-439X

\section{REFERENCES}

1 Schulenberg J, Johnston L, O'Malley P, et al. Monitoring the future national survey results on drug use, 1975-2019: volume II, college students and adults ages 19-60, 2020.

2 Galstyan E, Galimov A, Sussman S. Commentary: the emergence of pod Mods at Vape shops. Eval Health Prof 2019;42:118-24.

3 Leventhal AM, Miech R, Barrington-Trimis J, et al. Flavors of e-cigarettes used by youths in the United States. JAMA 2019;322:2132-4.

4 US Food and Drug Administration. Path study findings give insight into flavored tobacco, health effects of e-cigarettes, and adult use of Cigars and Hookah, 2020. Available: https://www.fda.gov/tobaccoproducts/research/path-study-findings-give-insight-flavoredtobacco-health-effects-e-cigarettes-and-adult-use-cigars [Accessed July, 12 2021].

5 US Food and Drug Administration. FDA finalizes enforcement policy on unauthorized flavored cartridge-based e-cigarettes that appeal to children, including fruit and mint, 2020. Available: https://www.fda. gov/news-events/press-announcements/fda-finalizes-enforcement- 
policy-unauthorized-flavored-cartridge-based-e-cigarettes-appealchildren [Accessed July, 12 2021].

6 Hemmerich N. Flavoured pod attachments score big as FDA fails to enforce premarket review. Tob Control 2020;29:tobaccocontrol2020-055718.

7 Williams R. The rise of disposable JUUL-type e-cigarette devices. Tob Control 2020;29:tobaccocontrol-2019-055379.
8 Dai H, Hao J. Online popularity of JUUL and puff bars in the USA: 2019-2020. Tob Control 2020;381:tobaccocontrol-2020-055727.

9 Wang TW, Gentzke AS, Neff LJ, et al. Disposable e-cigarette use among U.S. youth - an emerging public health challenge. $N$ Engl $J$ Med Overseas Ed 2021;384:1573-6.

10 Galimov A, Galstyan E, Yu S, et al. Predictors of Vape shops going out of business in southern California. Tob Regul Sci 2020;6:187-95. 